\title{
STEPS TOWARDS THE DEVELOPMENT OF AN EXPERIMENTALLY VERIFIED SIMULATION OF POOL NUCLEATE BOILING ON A SILICON WAFER WITH ARTIFICIAL SITES
}

\author{
A. Sanna ${ }^{1}$, T.G. Karayiannis ${ }^{1}{ }^{*}$, D.B.R. Kenning ${ }^{1}$, C. Hutter ${ }^{2}$, K. Sefiane ${ }^{2}$, A.J. Walton ${ }^{2}$, \\ I. Golobič ${ }^{3}$, E. Pavlovič ${ }^{3}$, and R.A. Nelson ${ }^{4}$ \\ ${ }^{1}$ Brunel University, Uxbridge, Middlesex UB8 3PH, UK, ${ }^{2}$ University of Edinburgh, Edinburgh, EH9 3JL, UK, \\ ${ }^{3}$ University of Ljubljana, Ljubljana, Slovenia, ${ }^{4}$ Los Alamos National Laboratory, Los Alamos, NM 87545, USA \\ *tassos.karayiannis@brunel.ac.uk
}

Nucleate boiling is a very effective heat transfer cooling process, used in numerous industrial applications. Despite intensive research over decades, a reliable model of nucleate pool boiling is still not available. This paper presents a numerical and experimental investigation of nucleate boiling from artificial nucleation sites.

The numerical investigation described in the first section of the paper is carried out by a hybrid mechanistic numerical code first developed at the University of Ljubljana to simulate the temperature field in a heated stainless steel plate with a large number of nucleation sites during pool boiling of water at atmospheric pressure. It is now being redeveloped to interpret experiments on pool boiling at artificial sites on a silicon plate and as a design tool to investigate different arrangements of sites to achieve high heat fluxes. The code combines full simulation of the temperature field in the solid wall with simplified models or correlations for processes in the liquid-vapour region. The current capabilities and limitations of the code are reviewed and improvements are discussed. Examples are given of the removal of computational constraints on the activation of sites in close proximity and improvements to the bubble growth model. Preliminary simulations are presented to compare the wall conditions to be used in the experiments on silicon at Edinburgh University with the conditions in current experiments on thin metal foils at Ljubljana.

An experimental rig for boiling experiments with artificial cavities on a $0.38 \mathrm{~mm}$ thick silicon wafer immersed in FC-72, developed at Edinburgh University, is described in the second part of the paper.

\section{NOMENCLATURE}

\begin{tabular}{|c|c|}
\hline$A$ & surface area of the dome $\left[\mathrm{m}^{2}\right]$ \\
\hline$D$ & diameter $[\mathrm{m}]$ \\
\hline$f$ & frequency $[\mathrm{Hz}]$ \\
\hline$H$ & artificial cavity depth $[\mathrm{m}]$ \\
\hline$h$ & heat transfer coefficient $\left[\mathrm{W} \mathrm{m} \mathrm{m}^{-2} \mathrm{~K}^{-1}\right]$ \\
\hline$k$ & thermal conductivity $\left[\mathrm{W} \mathrm{m}{ }^{-1} \mathrm{~K}^{-1}\right]$ \\
\hline$\dot{Q}$ & heat transfer rate $[\mathrm{W}]$ \\
\hline$q$ & heat flux $\left[\mathrm{W} \mathrm{m} \mathrm{m}^{-2}\right]$ \\
\hline$r$ & radius $[\mathrm{m}]$ \\
\hline$S$ & spacing between two cavities [m] \\
\hline$T$ & temperature $\left[{ }^{\circ} \mathrm{C}\right]$ \\
\hline$\Delta T$ & fraction of activation superheat $\left[{ }^{\circ} \mathrm{C}\right]$ \\
\hline$t$ & time $[s]$ \\
\hline$y, z$ & coordinates $[\mathrm{m}]$ \\
\hline
\end{tabular}

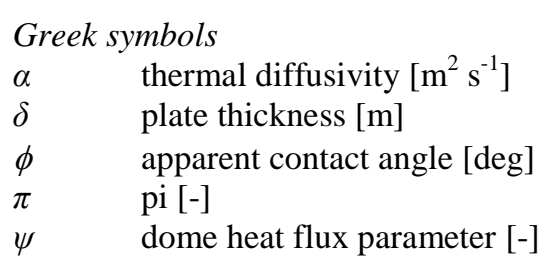

\begin{tabular}{ll}
\multicolumn{2}{l}{ Subscripts } \\
$O$ & initial condition \\
$b$ & bubble \\
$c$ & contact \\
$C$ & coalescence \\
cav & cavity \\
$D$ & dome \\
$d$ & departure \\
$i$ & generic site \\
$l$ & liquid \\
$m$ & mesh
\end{tabular}

\section{INTRODUCTION}

Most applications and studies of nucleate boiling heat transfer have been for metallic surfaces, on which the spatial and size distributions of nucleation sites can only be controlled in a general way during manufacture. Applications of boiling to the cooling of devices microfabricated on silicon open the way to the creation of large arrays of closely-spaced nucleation sites of specified microgeometry. Theoretical methods are required to optimise the design of the arrays in a rational way that takes account of the interactions between the sites. 
Interactions occur by a number of thermo-hydrodynamic mechanisms in the liquid-vapour region that may be coupled to interactions by conduction in the heated wall. Three-dimensional numerical simulations of the combined fluid-solid regions are currently limited to interactions between a few sites, e.g. Mukherjee and Dhir (2004), Dhir (2006), and have a minimum spatial resolution that is usually larger than the radius of typical nucleation sites. Hybrid mechanistic simulations, reviewed by Kenning et al. (2006), replace the accurate simulation of events in the fluid region by simplified physical models, correlations and networking rules, e.g. for site activation, bubble growth and departure, seeding of unstable sites and local heat transfer. Nelson and colleagues at Los Alamos National Laboratory developed a hybrid model to investigate the influence of wall properties on interactions by conduction between hundreds of sites, Pasamehmetoglu and Nelson (1991). The transient conduction equation was solved numerically on a 3-D rectangular grid representing the wall, with nucleation sites having different activation superheats placed at selected grid nodes at the wall-fluid interface. Bubble-related events in the fluid were represented by very simple sub-models. These models were later modified to simulate boiling at high heat flux with vapour chimneys through a liquid macrolayer between the wall and a hovering bubble, Sadasivan et al. (1995). Golobič et al. (1996a,b) at Ljubljana University developed a version of the low-flux model, in which sites could be placed at any position and the computational grid was refined temporarily in a cylindrical region under every growing bubble. The bubble growth sub-model was a simplified version of the Stephan and Hammer (1994) model for evaporation at a triple contact line, now regularly employed in 3-D numerical simulations of bubble growth, as in Dhir (2006). Only interactions transmitted through the wall were included in the model.

The validation of a multi-site model against experimental data for boiling on metal surfaces is difficult because there are few sufficiently detailed data sets to provide input information about site positions and characteristics in addition to data to test the model, and because the potentially chaotic nature of boiling (Nelson et al., 1996, Mosdorf and Shoji, 2004) requires statistical methods, Kenning et al. (2006). These issues were explored by comparing the Ljubljana model with liquid crystal measurements of the spatio-temporal temperature fields on the back of a thin stainless steel plate during the boiling of water, Golobič et al. (2004), during which bubbles were detected by computerised image analysis at 1505 locations, most of which were concentrated in 16 dense clusters. The poor agreement between the data and the model may have been caused by a combination of shortcomings in the data and the very simple sub-models used in the simulation. Sub-models may be improved by comparisons with experimental data and fully-3D simulations for isolated sites. Golobič et al. (2007a,b) measured wall temperature fields with higher spatial and temporal resolution by IR thermography during isolated bubble growth and bubble coalescence on very thin metal foils. The observations suggested that the contact line evaporation model for bubble growth was not appropriate for these particular conditions. Well before the advent of the triple contact line model, different modes of bubble growth were noted by Chesters (1978), Fig. 1, illustrated here by the differences in bubble growth and detachment during boiling of water from natural sites on a thin metal foil (Golobič et al., 2007b), Fig. 2(a), and from micromachined sites on a thick silicon disk (Mosdorf and Shoji, 2004), Fig. 2(b). The internal geometry of nucleation sites influences bubble production, Shoji et al. (2005).

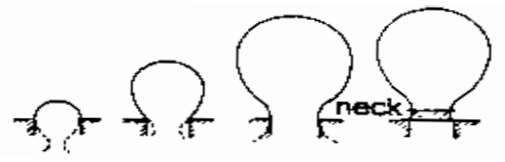

slow, confined to nucleation site

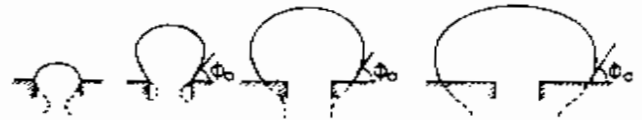

slow, spreading (fast with contact line evaporation)

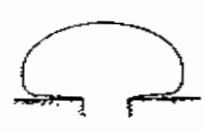

fast, microlayer

Figure 1: Bubble growth modes, after Chesters (1978)

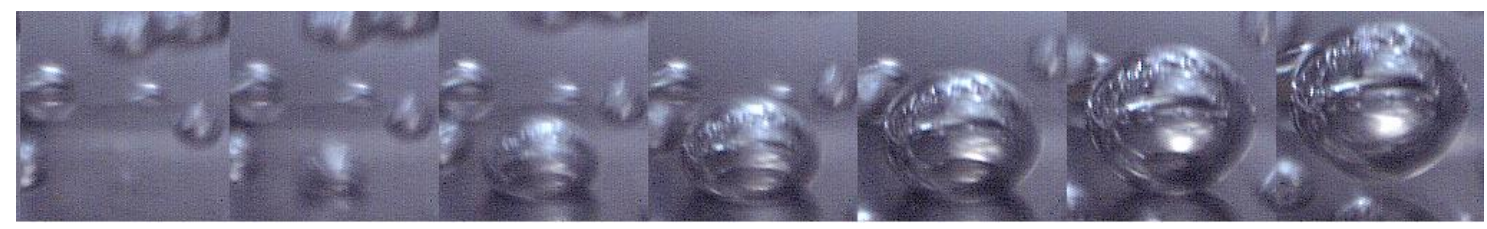

(a)

Figure 2: Bubble growth in water on

(a) a titanium foil (Golobič et al., 2007b)

(b) a silicon disk (Mosdorf and Shoji, 2004)
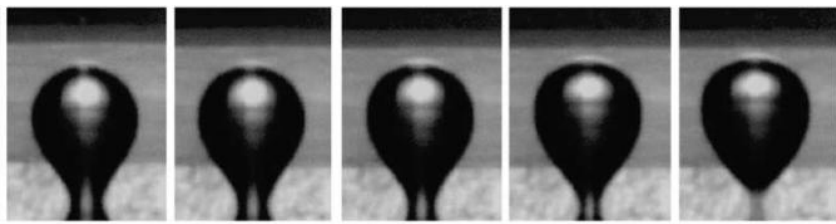

(b) 
Microfabricated sites on silicon provide much greater control over site positions and characteristics than can be achieved with natural sites on metal surfaces. Shoji and co-workers at Tokyo University used this approach for an exhaustive investigation of the thermo-hydrodynamic interactions between sites, e.g. Zhang and Shoji (2003), Chatpun et al. (2004), Shoji et al. (2005). Experiments were conducted on a silicon wafer (thickness 0.2 $\mathrm{mm}$, diameter $15 \mathrm{~mm}$ ) with cylindrical cavities (diameter $10 \mu \mathrm{m}$, depth $80 \mu \mathrm{m}$ ) arranged as single or twin cavities with different spacing $S(1,2,3,4,6$ and $8 \mathrm{~mm})$. The boiling liquid was saturated water and the silicon wafer was heated uniformly from below by laser irradiation. Temperature fluctuations on the rear of the wafer were measured along lines through the centres of cavities with an IR camera in line-scanning mode (spatial resolution $120 \mu \mathrm{m}$, temperature resolution $0.08 \mathrm{~K}$ and time resolution $3 \mathrm{~ms}$ ). Three types of interaction were identified: thermal interaction between nucleation sites, hydrodynamic interaction between bubbles (long-range, transmitted through the fluid) and horizontal and declining bubble coalescence (lateral, short-range). Their ranges of influence on average bubble departure frequency are shown in Fig. 3 in terms of the ratio of the spacing parameter $S$ to a characteristic bubble dimension $D_{b}$. Recently Sato et al. (2007), used a similar experimental setup with a single site or triple in-line sites at $S=1,2,3,4 \mathrm{~mm}$ that produced bubbles with departure diameters in the range $2.5-3 \mathrm{~mm}$. They performed chaos analysis of the time series for bubble growth and wall temperature at the single and central sites by constructing return maps, using delay times much smaller than the bubble growth time. They concluded that bubble growth at a single site was nearly deterministic but that the frequent coalescence between bubbles at triple cavities with $S \leq 3 \mathrm{~mm}$ made bubble diameter deterministically unpredictable over a long time period. The attractors of wall temperature for interacting sites had some structure indicative of chaotic complexity, rather than random variation. Interaction disappeared for $S \geq 4 \mathrm{~mm}$.

There were some differences between the findings of Shoji et al. (2005) and those of Gjerkěs and Golobič (2001, 2003) for long-range interactions between natural sites on a metal foil and a site controlled by localized heating by a

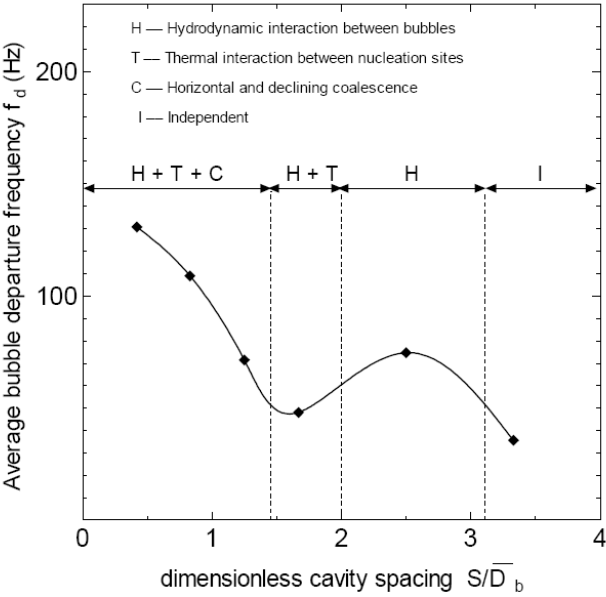

Figure 3: Site interactions, Shoji et al. (2005). focussed laser, using different measures of intensity. Golobič et al. (2007a,b) later measured with a high-speed, high resolution IR camera the two-dimensional temperature fields under isolated and coalescing sites on metal foils.

An alternative approach is to micro-fabricate on a transparent, electrically-insulating substrate a closelyspaced array of electrical resistance heaters, each with its own control system so it can be run either at constant temperature or at constant heat flux. A design by Rule and Kim (1999) was improved, as described in Demiray and Kim (2004) and Myers et al. (2005) to give a boiling surface formed of 96 closely-spaced platinum resistance heater elements deposited a quartz wafer. Simultaneous high-speed images of bubbles in boiling FC72 were taken through the semi-transparent heaters. Cheng and Chung (2003) investigated coalescence with a similar array, initiating nucleation by pulse heating of individual elements. This is a way of avoiding the difficulties of hysteresis and irregular activation at natural and artificial cavity sites.

It is clear that experimental studies of bubble growth, detachment and interaction ranging from detailed studies of heat transfer patterns around individual nucleation sites to studies of the networked interactions of a large population of sites covering a large area lead to conflicting requirements for instrumentation and data analysis. The translation of experimental measurements into simple rules for the physics sub-models in hybrid models for numerical simulation is not straightforward and the hybrid models must be sufficiently flexible to accommodate different modes of bubble growth.

\section{OBJECTIVES}

This paper reports progress on a project to develop the Ljubljana code into a design tool for arrays of micromachined nucleation sites to achieve high rates of cooling of silicon chips by pool boiling. The developments will include improvements to the physical sub-models and to numerical procedures to increase computational speed and remove some current restrictions on physical modelling, together with more formal Verification and Validation of the code than has been attempted previously. The first part of the paper describes the structure of the Ljubljana model and code, identifies aspects requiring development and gives some examples of work done so far.

The development of the physical sub-models will depend on experiments at Edinburgh University on boiling of FC-72, and later water, on arrays of sites and micro-thermometers micro-fabricated on silicon. The 
experiments will also provide data for validation of the design code. Further information will be drawn from a separate investigation at Ljubljana University of pool boiling on thin metal foils, employing high-speed IR thermography to measure 2-D wall temperature variations, Golobič et al. (2007a,b).

The philosophy for design of the experiments is summarized in the second part of the paper.

\section{THE LJUBLJANA MODEL}

The code solves the 3-D transient conduction equation for the temperature distribution $T(x, y, z ; t)$ in a rectangular slab representing the heated wall of thickness $\delta$, with

1. specified edge boundary conditions, e.g. constant temperature, adiabatic or connection to unheated wall,

2. specified volumetric heat source (ohmic heating of metal foil) and/or

3. specified heat flux distribution $(x, y ; t)$ on rear surface $z=0$ (thin-film heaters on silicon),

4. specified positions and properties of potential nucleation sites on front surface $z=\delta$,

5. specified heat flux distribution $(x, y ; t)$ on $z=\delta$ (local thin-film heaters to trigger nucleation sites on silicon),

6. specified heat transfer coefficient distribution $h(x, y ; t)$ on $z=\delta$, supplied by approximate physics modules for bubble nucleation, growth, departure and coalescence, single phase convection and hydrodynamic interactions that replace accurate numerical simulation of fluid region.

The transient conduction equation is solved by a simple explicit method, with consequent limitations on numerical accuracy and stability. The basic computational mesh is temporarily refined in a cylindrical region round an active site during bubble growth from nucleation to detachment. The original version of the code, Golobič et al. (2004), employed an unstructured basic mesh, which was appropriate for very irregularly-spaced natural sites on a metal foil. This has been replaced by a rectangular mesh that is suitable for more regular arrays of artificial sites, saving some of the time required for mesh generation.

Originally, the mesh was refined in a region of fixed radius corresponding to the maximum contact radius, which occurred at detachment and which was specified at each site. In order to avoid overlapping of refined regions, nucleation of a new bubble had to be prohibited at sites close to a growing bubble, thus artificially preventing coalescence and in some circumstances forcing bubbles to grow alternately at a pair of sites. This constraint has been partially removed by improvements to the meshing procedure and the bubble growth model, so that the radius of the refined region grows in a series of steps to follow the contact radius of the bubble as it expands and then contracts in the approach to detachment, Fig. 4, and the introduction of an approximate model for coalescence, described below. The minimum distance between two sites allowed to be active at the same time was equal to the sum of their maximum contact radii, increased by $20 \%$ to allow at least one row of Cartesian unrefined cells between the refined regions. With the new procedure, combined with the variation of the apparent contact angle described below, the minimum distance can be reduced by more than $50 \%$ during the early stages of bubble growth. The procedure will be further improved to eliminate a loss of accuracy during mesh replacement due to the present impossibility of replacement of one circular mesh distribution by another without first merging cells into the original Cartesian grid. These improvements significantly increase the computing time and introduce small errors in calculations of bubble growth and temperature at the nucleation sites.

The code has been restructured by Nelson at LANL for parallel computation: running time has been strongly reduced; formal verification will be performed.

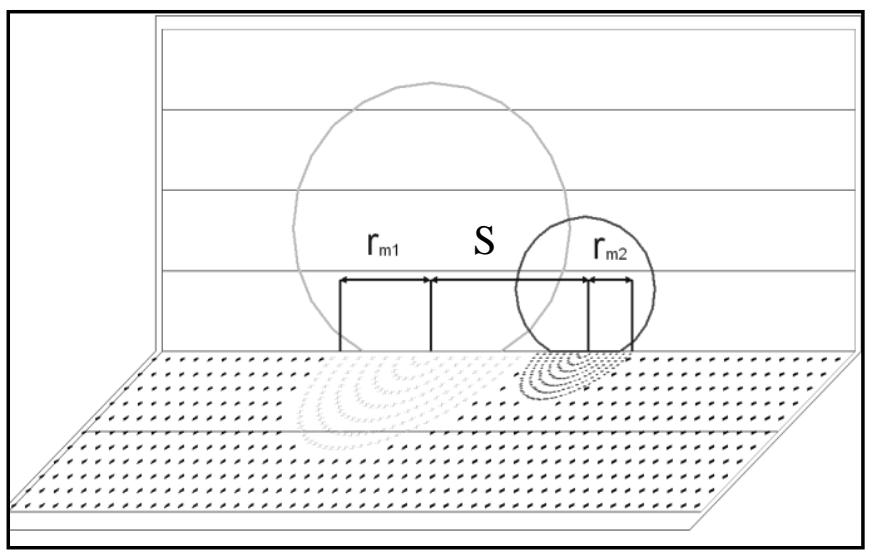

Figure 4: Mesh refinement scheme

The primary outputs from the code are the bubble radius $r_{b d, i}$, the contact radius $r_{c, i}$, the temperature $T_{i}$ and records of activity for each nucleation site and the instantaneous temperature $T(x, y ; t)$ and heat flux $q(x, y ; t)$ distributions on the front surface $z=\delta$, which are used in the physics sub-models.

The current criterion for nucleation is that bubble growth commences when the local wall superheat rises to an activation superheat (corresponding to an equivalent critical radius) that has to be inserted as input datum for each potential nucleation site. Immediate nucleation of one bubble following the detachment of a preceding bubble is permitted but the thermo-fluid consequences of vertical coalescence of bubbles from the same site are 
not modelled at present. This may require future consideration because the experimental data for boiling on silicon wafers generally exhibit very short waiting times, whereas waiting times are long on thin metal foils.

This criterion is appropriate for nucleation at a critical radius within a cavity. It will be extended in due course to include the effect of the external temperature gradient in the liquid due to the local wall heat flux. Other influences that will be examined are hydrodynamic disturbances due to bubble growth at adjacent sites and seeding of unstable sites by vapour from a stable site in close proximity.

Approximate models have to be defined for the shape of the bubble, the various heat flows into it and its detachment. The original version of the code employed very simple models. The bubble was assumed to grow as a truncated sphere with a constant apparent contact angle $\phi$. Heat for evaporation was supplied only through the base of the bubble; heat transfer from the bulk liquid through the dome was neglected. Heat transfer through the base of the bubble was based on the Stephan and Hammer (1994) contact line concept. The contact area was divided into two concentric zones:

(i) a central circle covered by an adsorbed liquid film with a very low heat transfer coefficient;

(ii) an outer ring with a high heat transfer coefficient, representing the heat flow at the triple contact line. The width of the ring was much greater than the sub-micron length scale proposed in models of the contact zone and the heat transfer coefficient was reduced accordingly. The values of the heat transfer parameters were chosen to match growth rates with experimental observations. The effects of interfacial non-equilibrium at high heat fluxes were assumed to be included in the heat transfer coefficient, so that the vapour was at the saturation temperature.

The model for (i) was modified in the Golobič et al. (2004) version of the code to allow for the possible presence of liquid drops trapped in surface roughness in the adsorbed film region, by having a somewhat higher heat transfer coefficient at the nucleation site, decreasing linearly towards the triple contact line. Detachment occurred at a specified volume expressed as the equivalent radius of a sphere, with values obtained from correlations or experimental observations for individual sites.

Recent experiments with thin metal foils, Golobič et al. (2007a,b), have shown that heat transfer may be maintained over the entire contact area, with the highest heat transfer coefficient at its centre, decreasing radially without a maximum at the apparent contact line. The code has been modified so that any radial distribution of heat transfer coefficient may be specified; choice of the correct model depends on experiments. All the examples in this paper have been simulated using a zero heat flux in the inner area, a very high heat transfer coefficient for the ring containing the triple contact line and an enhanced natural convection heat transfer coefficient (not contributing to the bubble growth) for the ring outside the triple contact line region. The latter accounts the effect of movements of colder liquid from the region far from the bubble; example of this phenomenon can be observed in Golobič et al. $(2007 \mathrm{a}, \mathrm{b})$ that also measured an enhancement of the heat flux in a narrow ring just outside the expanding contact area in the early stages of bubble growth. When the contact area contracted prior to detachment, the heat flux measured at its periphery was reduced, instead of enhanced. Since contraction of the contact area is now included in the code, further investigation is required to determine how this effect may be represented in the hybrid model.

In its original form, the code applied a uniform and single phase heat transfer coefficient slightly dependent on temperature in the wall region outside the bubble contact area. Its value was taken from a standard correlation for natural convection on a horizontal plate. In addition, the code contained provision for enhanced single phase heat transfer in a circular area of influence immediately following bubble detachment at maximum contact radius, calculated by the "wall quenching" model of transient conduction to liquid at the bulk temperature. This feature of the code is not employed at present, because it greatly overestimated the heat transfer measured for conditions of rapid bubble growth followed by a long waiting time in experiments on thin metal foils, Golobič et al. $(2007 a, b)$. Further research is required to determine whether it may be appropriate in other conditions, e.g. when streams of bubbles are produced with small waiting times or in boiling at large subcooling.

In the current project, these modelling assumptions are being developed to improve their physical realism, usually at the cost of higher simulation time and introduction of more parameters that have to be specified in the computer code. The following improvements have now been implemented:

Heat transfer to the bubble dome has been added, estimated by

$$
\dot{Q}_{D}=\psi \cdot A \cdot k_{l} \Delta T(\pi \alpha \cdot t)^{-1 / 2}
$$

where $A$ is the surface area of the dome at time $t$ after nucleation, $\Delta T$ is a specified fraction (usually 0.5 ) of the activation superheat of the nucleation site, and $\psi$ is a parameter to fix the relative importance of the heat flux at the dome. During the following simulation, $\psi$ has been set equal to 1 .

The original assumption of constant apparent contact angle resulted in sudden detachment when the contact area was a maximum. The first method used to model detachment at zero contact area was to reduce the contact angle linearly with time after the bubble reached a defined fraction (e.g. 0.6) of the specified detachment radius. The sub-model required a manual determination of the correct rate of decrease to match original detachment 


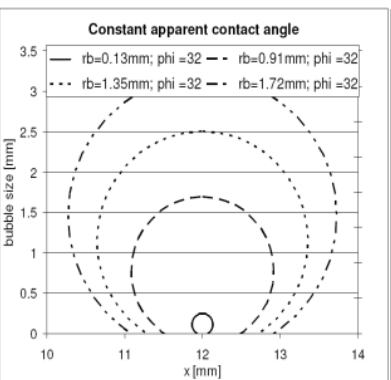

a

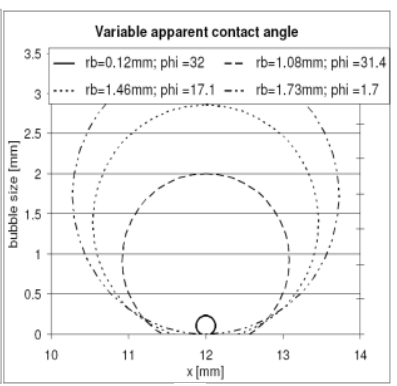

b

Figure 5 a, b: Apparent contact angle models (a) constant, (b) variable

conditions when the bubble radius reaches its maximum value. The linear dependence on time has been replaced by a linear decrease with the inverse of the bubble volume, as shown in Fig. 5a, b. This matches approximately the bubble evolution during boiling on a thin metal foil, Fig. 2a. A comparison of the use of constant and variable contact angles for a bubble detachment radius of $1.75 \mathrm{~mm}$ in water on a thin $(25 \mu \mathrm{m})$ titanium foil, with an equivalent heat flux of $50 \mathrm{kWm}^{-2}$ is shown in Fig. 6. Detachment with a zero apparent contact angle leads to an increase in growth time of approximately $10 \%$, and a decrease of waiting time. This is caused by the different temperature distribution around the nucleation site after detachment, as shown in Fig. 7. For the constant contact angle, a deep trough in the temperature profile, caused by previous cooling at the triple contact line, reduces the lateral heat flow towards the centre of the site, leading to a slower recovery. By contrast, for the variable contact angle simulation, the trough is at the centre, and the effect of lateral conduction, not relevant over a large scale for a thin foil as discussed later, becomes important for a short distance. The temperature profile and bubble period strongly depend on the contact angle rate of decrease and on the value of the fraction of the specified detachment radius at which the decrease is specified to start.

A second detachment model, in which a conical extension of the truncated sphere is introduced, to match a detachment shape approximating to Fig. $2 \mathrm{~b}$ is under development.

At present, the only hydrodynamically transmitted interaction between bubbles introduced into the code is a rudimentary model for coalescence. If two bubbles grow in close proximity, their domes will come into contact while their contact areas are still separate. Two situations are considered, both of which were observed in Golobič et al. (2007b):

(a) If the bubbles have similar size, Fig. 8a, they are assumed to continue growing as two independent isolated bubbles, but a dedicated heat transfer coefficient $\left(h_{C}\right)$ is defined for the region between them. In reality, immediately after coalescence, the bubble assumes the shape of a horizontally elongated bubble.

(b) If the sizes are sensibly different, Fig. 8b, the smaller bubble is assumed to be rapidly absorbed by the larger bubble, which undergoes a sudden increase in volume. A larger departure radius must then be specified for the combined bubble. Examples of the application of this model are given in a conference paper, Sanna et al. (2008).

\section{PRELIMINARY RESULTS}

Two simulations have been run to evaluate the influence of the different wall characteristics for experiments in Ljubljana and Edinburgh Universities, using respectively a titanium foil $25 \mu \mathrm{m}$ thick with natural cavities and a silicon wafer $0.38 \mathrm{~mm}$ thick with micromachined cavities. Table 1 summarizes the characteristic of the two plates. Saturated water at atmospheric pressure has been used for both simulations, although initial experiments 
in Edinburgh employ FC-72. All other inputs to the code are the same (bubble departure radius, activation temperature, apparent contact angle, heat transfer coefficients). The disposition of the nucleation sites has been chosen to avoid coalescence but to allow the possibility of thermal interaction. In order to reduce computing time, the number of sites has been kept small and a low level of grid refinement has been used. Consequently, the grid values in plots of the radial distributions of temperature and heat flux are joined by straight lines.

Table 1: Characteristic of the plate

\begin{tabular}{|c|c|c|c|c|c|c|}
\hline & material & $\begin{array}{c}\text { thickness } \\
{[\mu \mathrm{m}]}\end{array}$ & $\begin{array}{c}\text { conductivity } \\
{\left[\mathrm{W} \mathrm{m}^{-1} \mathrm{~K}^{-1}\right]}\end{array}$ & $\begin{array}{c}\text { density } \\
{\left[\mathrm{kg} \mathrm{m}^{-3}\right]}\end{array}$ & $\begin{array}{c}\text { specific heat } \\
{\left[\mathrm{J} \mathrm{kg}^{-1} \mathrm{~K}^{-1}\right]}\end{array}$ & $\begin{array}{c}\text { thermal } \\
\text { capacity } \\
{\left[\mathrm{J} \mathrm{m}^{-2} \mathrm{~K}^{-1}\right]}\end{array}$ \\
\hline titanium foil & $\mathrm{Ti}$ & 25 & 21.9 & 4500 & 523 & 58.8 \\
\hline silicon wafer & $\mathrm{Si}$ & 380 & 110 & 2340 & 750 & 667 \\
\hline
\end{tabular}

The geometry used for the simulations was a $24 \times 24 \mathrm{~mm}$ solid plate with seven potential active sites located at the centre in triangular symmetry at a spacing of $4 \mathrm{~mm}$. Fig. 9 shows the mesh distribution when all the sites are active with each dot representing the centre of a cell mesh. The site activation temperature is $115.5^{\circ} \mathrm{C}$. The bubble departure diameter is $3.5 \mathrm{~mm}$, with an initial apparent constant angle of $32^{\circ}$. The contact angle reduction model has been used and the uniform volumetric heat source corresponds to an input heat flux of $50 \mathrm{kWm}^{-2}$. The bottom of the plate is adiabatic and its edges are kept at a constant temperature of $125{ }^{\circ} \mathrm{C}$, approximately equal to the equilibrium temperature in the case of pure natural convection cooling.

\section{Comparison between simulations for $\mathrm{Ti}$ and $\mathrm{Si}$ plates}

Representative distributions of wall surface temperatures on a line passing through sites 5 - 1 - 2 are shown in Figs. 10

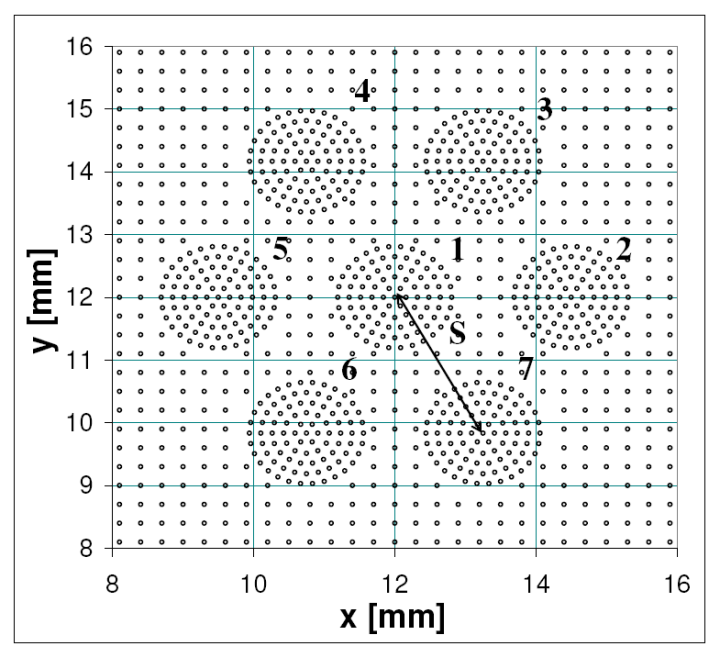

Figure 9: Mesh distribution and 11 for titanium and silicon respectively. The restricted edge effects and the large areas of uniform temperature outside the area influenced by the cluster of sites in Fig. 10 indicate that lateral conduction is very small because of the small thickness of the titanium foil. The temperature between the sites is nearly the same as the undisturbed temperature, so there is hardly any thermal interaction between the sites. Each site has to remove only the heat supplied in its immediate vicinity. Because of the slight differences in conditions, bubbles at the different sites grow out of phase but over a long period of simulation their growth characteristics are similar, Table 2. Because of the low thermal capacity of the titanium foil, there are large variations in the local temperature, falling to within $4 \mathrm{~K}$ of the saturation temperature under the bubbles. By contrast, everywhere on the thicker silicon wafer in Fig. 11 is influenced by lateral conduction. There are large flows of heat to the edges and towards the cluster of sites, which must therefore remove more heat than the sites on the titanium foil for the same uniform heat input. The total volumetric production of vapour is therefore increased and, because the bubble departure volume is fixed in the simulations, the computed bubble periods are reduced. There is a strong thermal interaction between the sites on silicon and the outer sites receive more heat by lateral conduction than the central site. The local fluctuations in temperature are reduced by the much larger thermal capacity of the

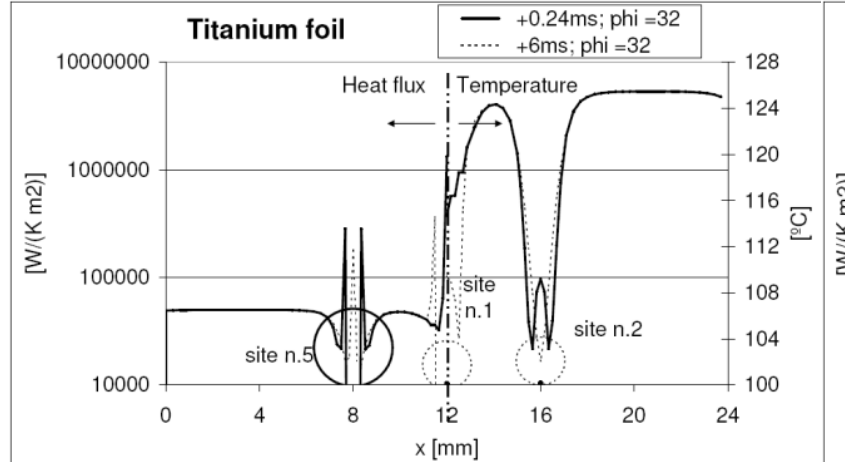

Figure 10: Heat flux and temperature distributions for titanium foil

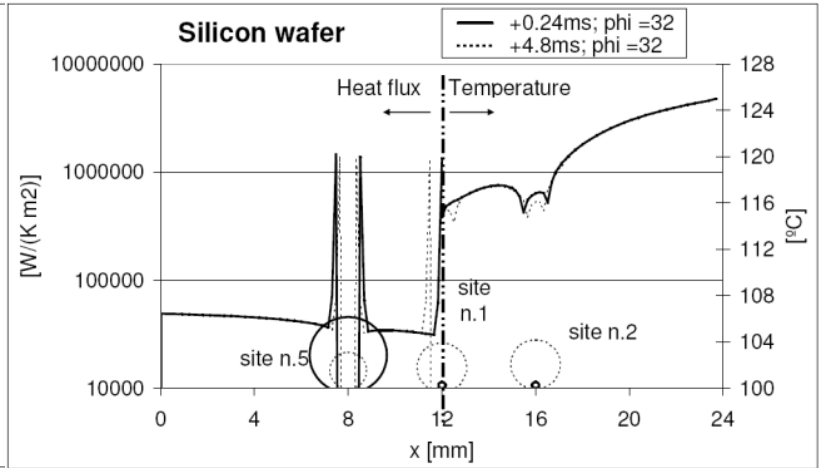

Figure 11: Heat flux and temperature distributions for silicon wafer 
silicon wafer and the higher transient lateral conduction. The computed bubble periods, growth and waiting times for each site on the two materials are compared in Table 2. The absence of thermal interaction on the titanium foil results in similar times at all the sites. On silicon, all the sites have similar growth times that are sensibly shorter than on titanium, because the wall superheat is less depressed. The waiting times at the outer sites are negligible, which is consistent with experimental observations of boiling on silicon. The waiting time at the central site is marginally longer, because it receives less heat by lateral conduction than the outer sites.

Table 2. Bubble periods and growth times for titanium and silicon plates

\begin{tabular}{|c|c|c|c|c|c|c|c|c|}
\hline \multicolumn{2}{|c|}{ site } & 1 & 2 & 3 & 4 & 5 & 6 & 7 \\
\hline \multirow{3}{*}{$\mathrm{Ti}$} & period [ms] & 28.14 & 29.09 & 27.76 & 27.76 & 29.09 & 27.76 & 27.76 \\
\cline { 2 - 9 } & growth time [ms] & 19.38 & 19.78 & 19.53 & 19.53 & 19.78 & 19.52 & 19.52 \\
\cline { 2 - 9 } & waiting time [ms] & 8.77 & 9.31 & 8.23 & 8.23 & 9.31 & 8.23 & 8.23 \\
\hline \multirow{3}{*}{$\mathrm{Si}$} & period [ms] & 14.74 & 13.91 & 13.84 & 13.84 & 13.91 & 13.85 & 13.84 \\
\cline { 2 - 9 } & growth time [ms] & 14.44 & 13.9 & 13.83 & 13.83 & 13.9 & 13.84 & 13.83 \\
\cline { 2 - 9 } & waiting time [ms] & 0.3 & 0.01 & 0.01 & 0.01 & 0.01 & 0.01 & 0.01 \\
\hline
\end{tabular}

For both materials, there is a rapid initial reduction in the wall temperature at the nucleation site when the contact area is very small, because of the assumed very high heat transfer coefficient at the position of the triple contact line. As this region of high heat transfer coefficient moves outwards with the contact line, the reduction in temperature also moves outwards. There is a gradual recovery in the wall superheat at the nucleation site, as it is subjected to a much lower heat transfer coefficient. On the titanium foil, the wall superheat falls initially to less than $7^{\circ} \mathrm{C}$, consequently limiting the heat flux, Fig. 12. The changes in superheat are smaller on the silicon wafer, with a reduction of $2-3{ }^{\circ} \mathrm{C}$, because of its much larger thermal capacity, combined with lateral conduction, Fig. 13. After the contact area reaches its maximum size and the contact line starts to move back towards the nucleation site, the region of high heat transfer coefficient moves back with it but the heat flux is strongly dependent on the pre-cooling of the wall during the previous expansion. There is a large effect for the titanium foil, Fig. 14. The inward-moving peak of high heat flux is followed by a narrow trough of reduced heat flux as liquid with a low heat transfer coefficient floods back into the pre-cooled contact area. This trough reproduces qualitatively the observations of Golobič et al. (2007a,b) for boiling on metal foils, noted earlier. The temperature and heat flux remain much higher on the silicon wafer, Fig. 15.

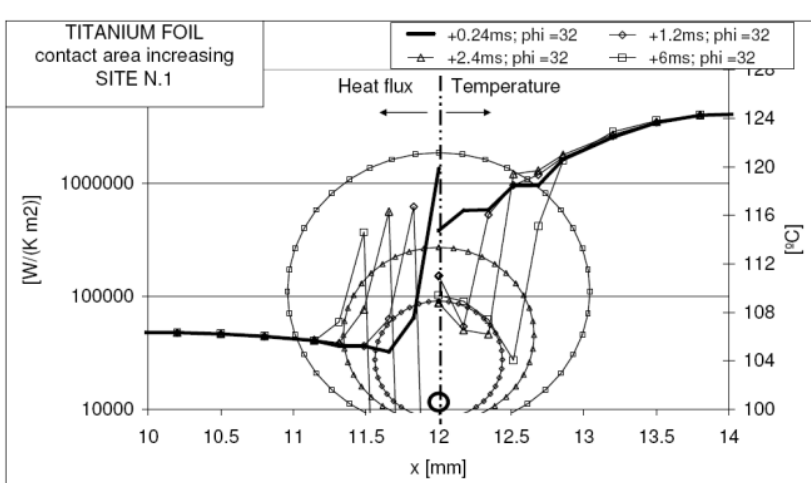

Figure 12: Heat flux and temperature distributions for titanium foil - contact area increasing

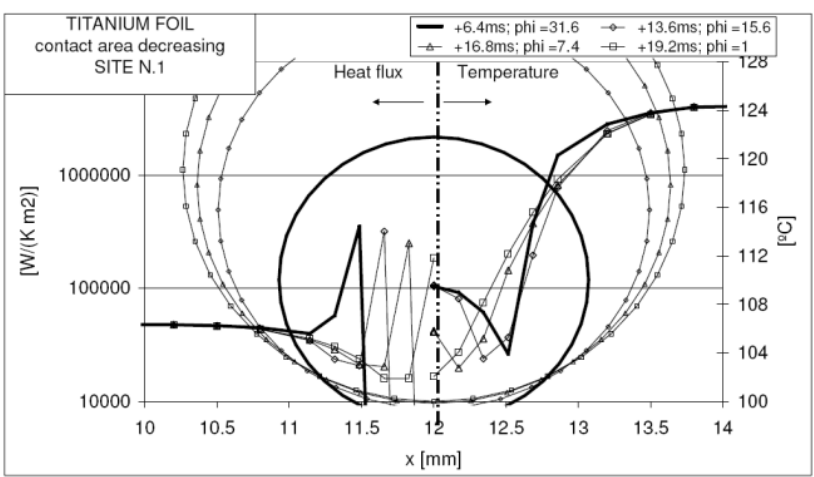

Figure 14: Heat flux and temperature distributions for titanium foil - contact area decreasing

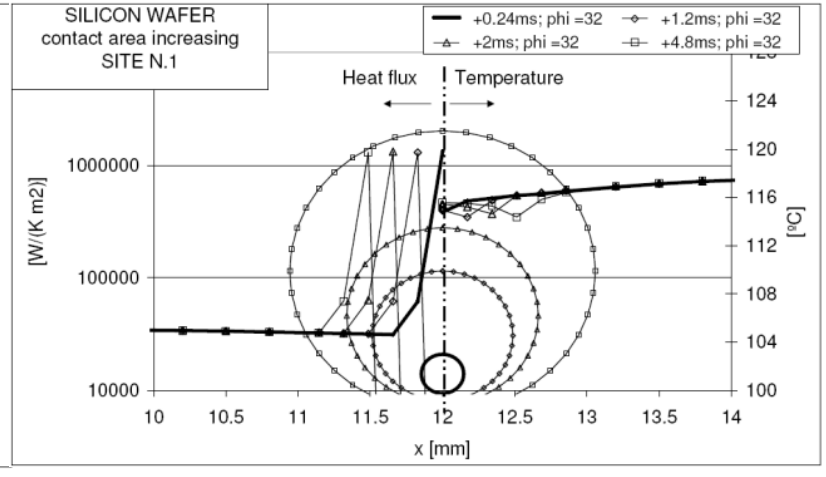

Figure 13: Heat flux and temperature distributions for silicon wafer - contact area increasing

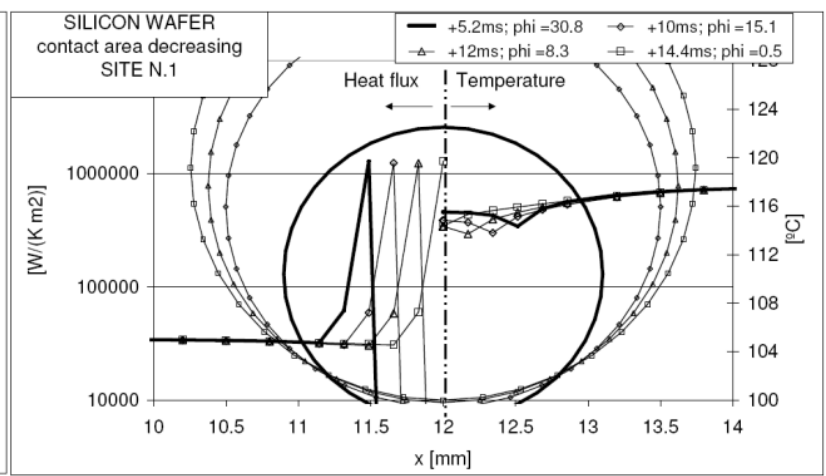

Figure 15: Heat flux and temperature distributions for silicon wafer - contact area decreasing 
As the peak in heat transfer coefficient and therefore in heat flux returns towards the nucleation site, just before detachment, the superheat there falls again, Figs. 16 and 17. The time taken for the superheat to recover to the activation superheat required to trigger the next bubble depends on the value of this second minimum in the superheat, the thermal capacity of the wall and the imbalance between heat input by generation and lateral conduction and heat removal by single-phase convection.

The model assumes that growth is driven by the heat flux through the contact area and also by transient conduction from the superheated liquid to the dome of the bubble. This second contribution is not affected by the cooling of the wall so it becomes relatively more important for bubble growth on the titanium foil than on the silicon wafer, as shown in Figs. 18, 19.

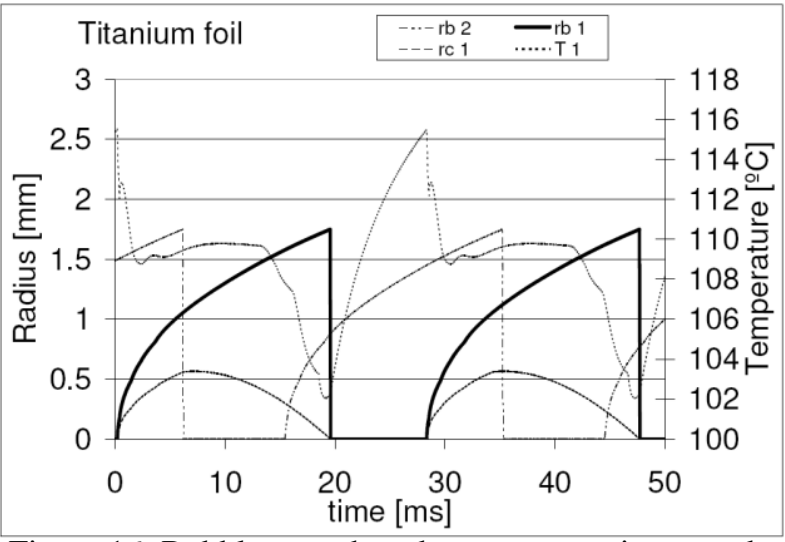

Figure 16: Bubble growth and temperature time-trends for the titanium foil

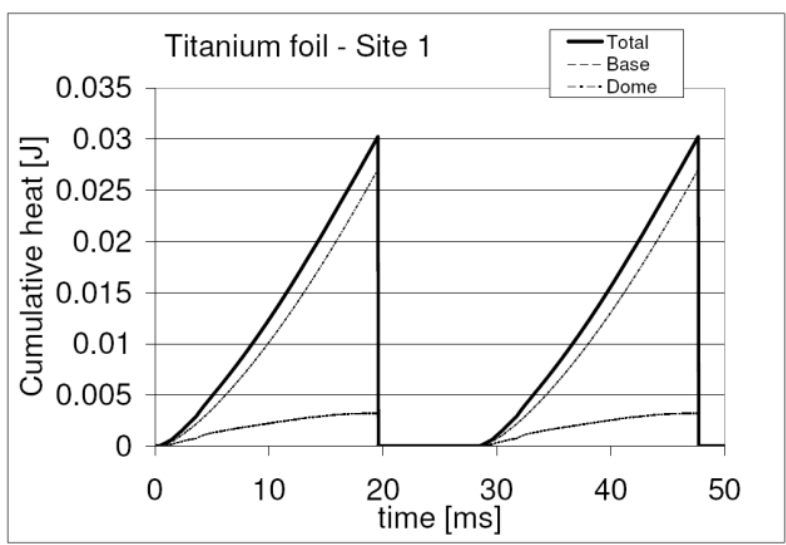

Figure 18: Cumulative heat for the titanium foil

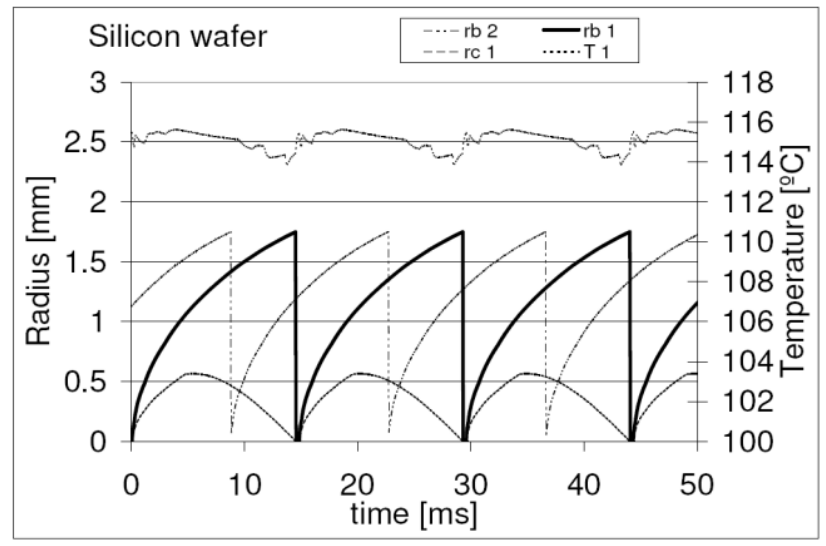

Figure 17: Bubble growth and temperature time-trends for the silicon wafer

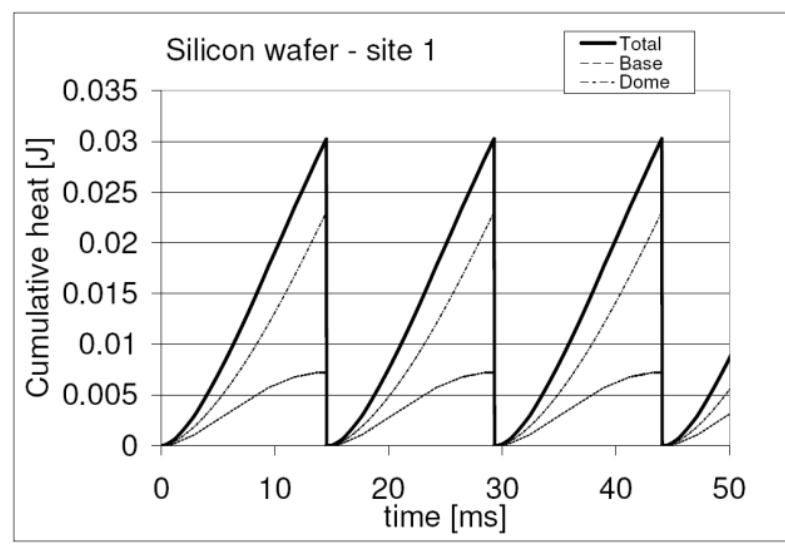

Figure 19: Cumulative heat for the silicon wafer

\section{Comments}

These preliminary examples have employed an established model for bubble growth driven partly by intense evaporation at a moving triple-contact line. The radial distributions of heat flux calculated by the model are different in nature from those observed by Golobič et al. $(2007 \mathrm{a}, \mathrm{b})$ for boiling on a $25 \mu \mathrm{m}$ thick titanium foil, despite the apparent success in modelling a local trough in the heat flux during contraction of the contact area but much more work is required to compare a variety of modelling assumptions with local measurements on thin metal foils and on thicker silicon wafers. The code has the necessary flexibility to do this and the examples have demonstrated its usefulness in exploring the influence of wall conditions on thermal interactions between bubble nucleation sites. Significant variations in local wall temperature may occur during boiling on a silicon wafer, even at the low heat flux of $50 \mathrm{kWm}^{-2}$ used in the examples. The waiting time between bubbles, important in determining the cooling capability of a nucleation site, is large on the titanium foil but very small on the silicon wafer. In other circumstances, it may depend delicately on the interaction between the mechanism of heat transfer in the contact area of the bubble and the properties of the heated wall. 


\section{EXPERIMENTAL PROGRAMME}

The experimental setup at Edinburgh is shown schematically in Fig. 20. The boiling chamber has four borosilicate glass windows, which allow optical access from the top, the bottom and two sides. A siliconeinsulated resistance heater is attached to the walls to reduce heat losses. The stainless steel rig is designed to operate over a range of pressures from atmospheric to 5 bars and a temperature up to $160{ }^{\circ} \mathrm{C}$. The pressure is controlled by the cooling liquid flow through the condenser coil regulated by a control valve. The boiling liquid is initially heated up with a flow heater. Two filters in the pipe system remove any particles contained in the boiling liquid and all part materials and seals are chosen such to prevent any contamination. All electrical connections pass through vacuum-tight seals to the computer data acquisition system. The refrigerant FC-72 was chosen as the working fluid for the preliminary tests, because being a dielectric it eliminates electrical insulation issues associated with water. The boiling temperature of FC-72 is about $56{ }^{\circ} \mathrm{C}$ at atmospheric pressure $(3 \mathrm{M}$ product information, 2000).

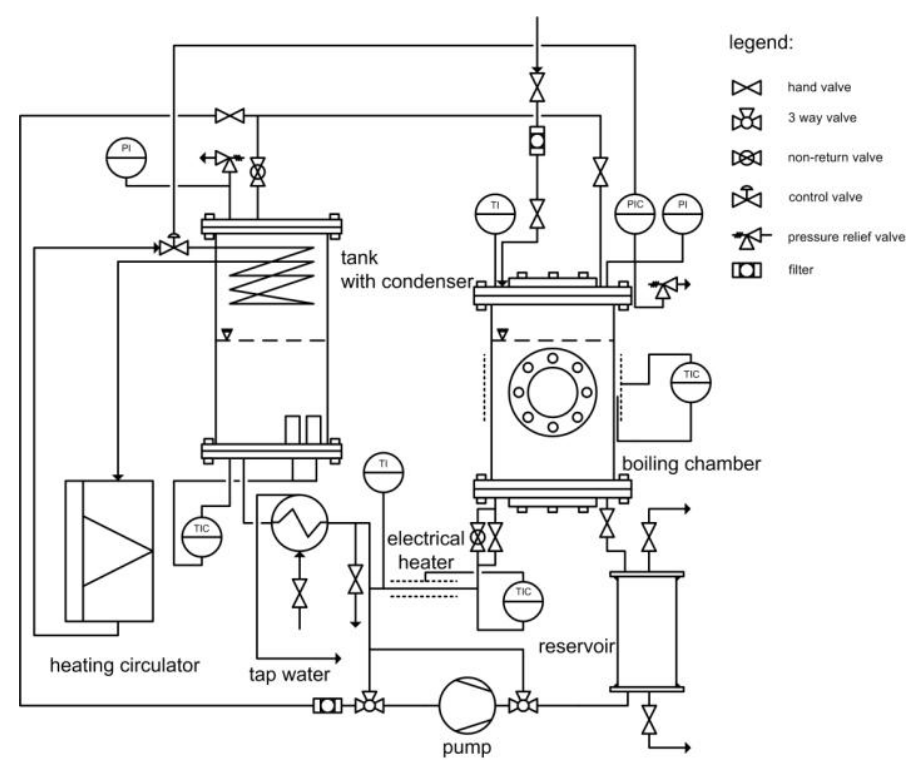

Figure 20: Schematic drawing of experimental rig including the main parts: boiling chamber and external condenser

Preliminary boiling tests were performed with FC-72 boiling at atmospheric pressure on a $76.2 \mathrm{~mm}$ diameter silicon wafer with a thickness $0.38 \mathrm{~mm}$. On the surface there were forty five $2 \mu \mathrm{m}$ diameter cylindrical cavities. These were approximately $22 \mu \mathrm{m}$ deep having been etched using the deep reactive ion etch (DRIE) Bosch process, Fig. 21. Heating with a flux density up to $15.5 \mathrm{kWm}^{-2}$ was provided over a diameter of $50.8 \mathrm{~mm}$ by a kapton-insulated resistance heater between the back of the wafer and a PTFE table. Back-lit images of boiling were recorded by a high speed digital camera operating at $1000 \mathrm{~Hz}$. At fluxes of $14.4 \mathrm{kWm}^{-2}$ nucleation was not confined to the cylindrical cavities and it was difficult to observe the activity on all cavities, Fig. 22.

Bubble formation was recorded at a single stable site at $11.7 \mathrm{kWm}^{-2}$ with similar bubbles being formed

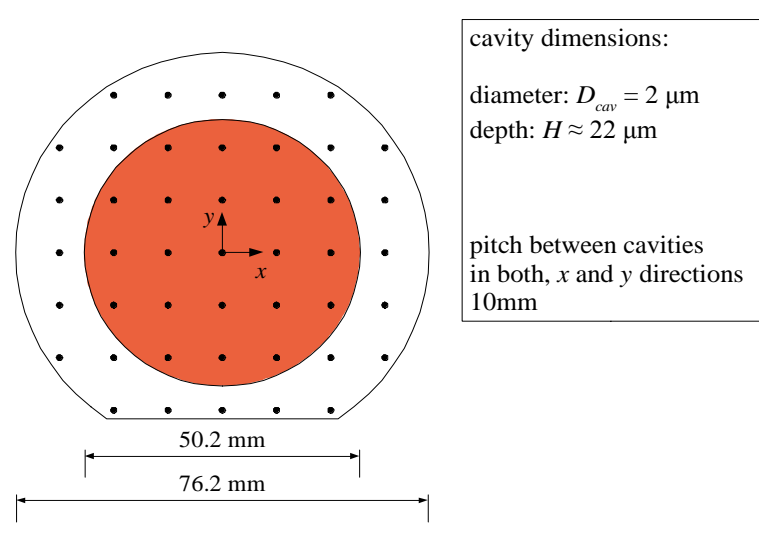

Figure 21: First test section with 45 cavities

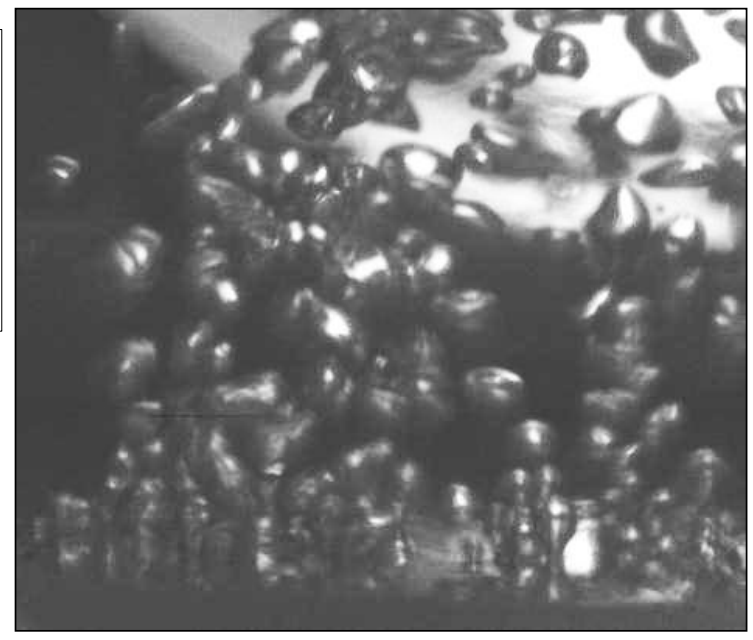

Figure 22: Boiling at $14.4 \mathrm{kWm}^{-2}$ 
continuously, with no waiting time, as shown in Fig. 23. There was a small decrease in the rate of growth, which approximately coincided with the maximum apparent contact radius. This may have been a consequence of the contact line receding over the pre-cooled wall as the bubble started to lift off. The bubble shape during detachment was similar to that for bubbles in water on silicon (Fig. 2b) rather than the more rounded shape for water on a titanium foil (Fig. 2a).

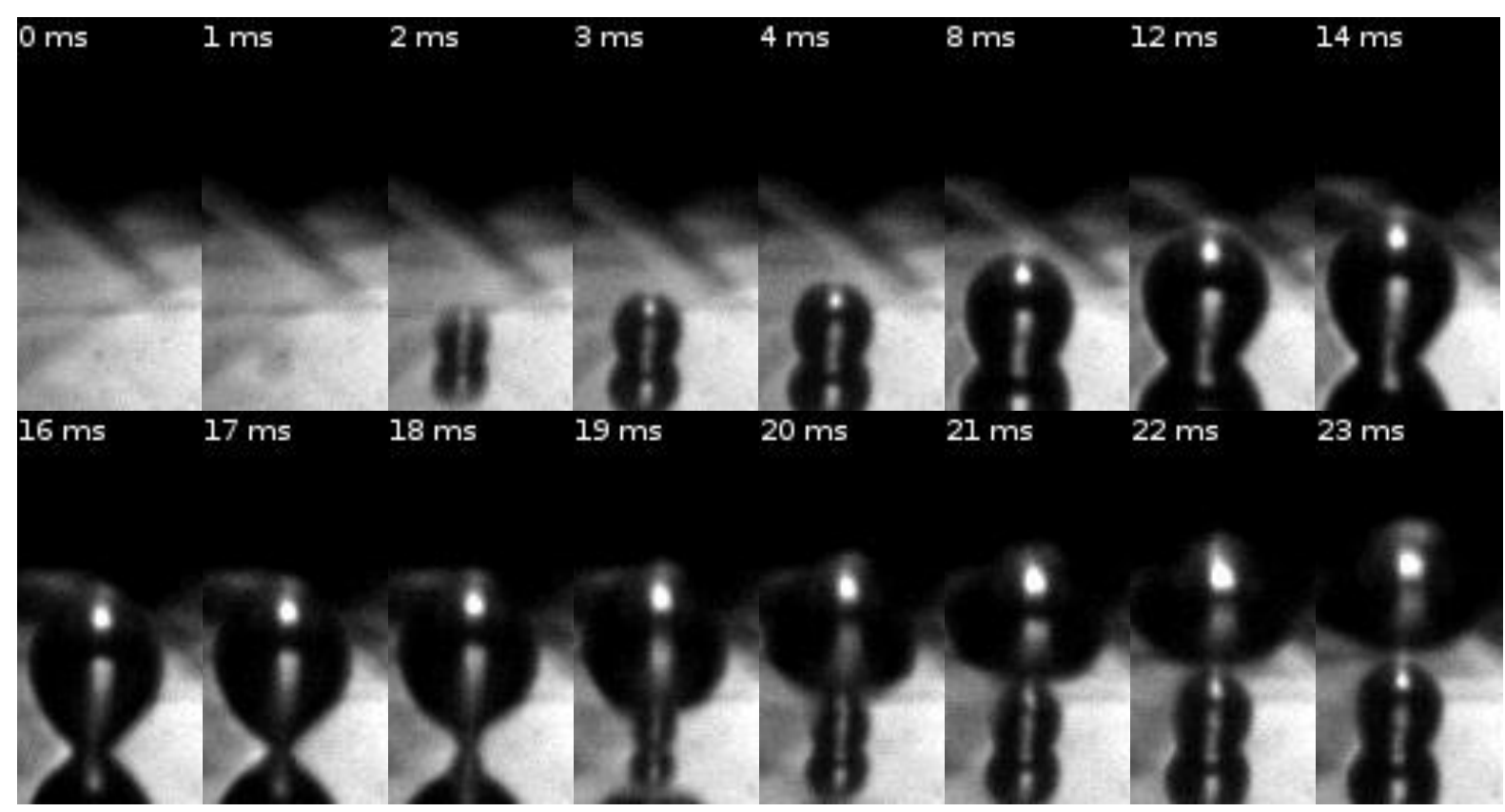

Figure 23: Bubble growth at $11.7 \mathrm{kWm}^{-2}$

The next version of the silicon test section will have an integrated heater on the back and micro-sensors below the artificial nucleation sites, as shown schematically in Fig. 24.

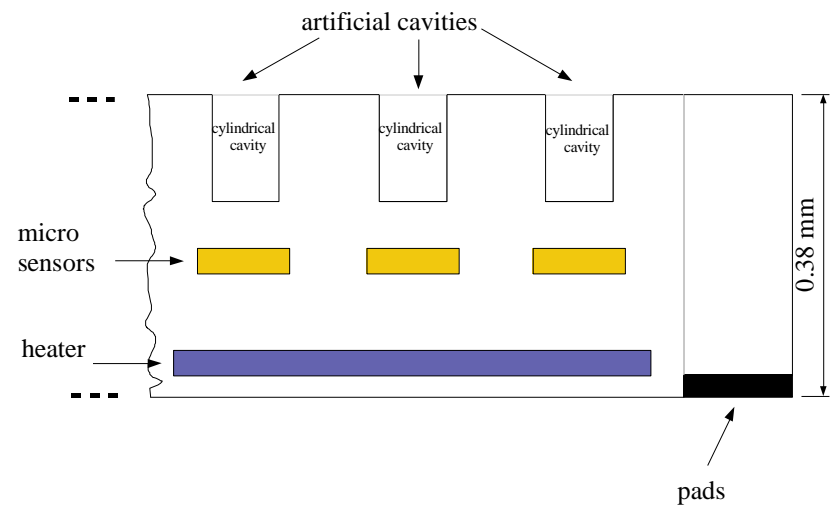

Figure 24: Schematic cross section view of the proposed silicon device with cavities, micro-sensors, background heater and insulation

\section{CONCLUSION}

This paper has reported on the early stages of a project to develop a numerical simulation of pool boiling as a design tool for arrays of micro-fabricated bubble nucleation sites to achieve the removal of high heat fluxes from a silicon chip. The simulation is based on numerical codes developed first at Los Alamos National Laboratory and then at Ljubljana University, employing a hybrid model in which 3-D analysis of conduction in the wall is combined with simple models for physical processes in the liquid-vapour region. Improvements to the 
bubble growth model with local refinement of the numerical mesh are described in the paper. These open the way to the inclusion of a model for the lateral coalescence of bubbles. The code has been restructured for parallel computing to meet the need for faster computation of more complicated models.

The simplified treatment of events in the liquid-vapour region necessarily relies heavily on experimental input. This information relies on very localised measurements taken during boiling on thin metal foils with natural nucleation sites in current experiments with high-speed IR thermography and from a newly commissioned rig employing a silicon wafer with micromachined cavities and integrated microsensors.

The numerical hybrid code has the flexibility to incorporate the experimental findings as they become available. Its capability to simulate the different wall conditions in the titanium foil and silicon wafer has been demonstrated by two examples. The simulations suggest that there are significant changes in the wall temperature during bubble growth and detachment, even on a material of high thermal conductivity like silicon.

\section{ACKNOWLEDGEMENT}

This work is supported by EPSRC Grants EP/C532805, EP/C532813/1. The authors are grateful for the help of Mr. G. Cummins and Dr. J. T. M. Stevenson at the Scottish Microelectronics Centre (SMC) Edinburgh in manufacturing the silicon devices.

\section{REFERENCES}

Chatpun, S., Watanabe, M., Shoji, M., 2004, Experimental Study on Characteristics of Nucleate Pool Boiling by the Effects of Cavity Arrangement, Experimental Thermal and Fluid Science Vol. 29, pp. 33-40.

Cheng, T. and Chung, J.N., 2003, Heat transfer effects of coalescence of bubbles from various site distributions, Proc. Roy. Soc. London, Ser. A 459, pp. 2497-2527.

Chesters, A.K., 1978, Modes of bubble growth in the slow-formation regime of nucleate pool boiling, Int. J. Multiphase Flow, Vol. 4, pp. 279-302.

Demiray, F. and Kim, J., 2004, Microscale Heat Transfer Measurements During Pool Boiling of FC-72, Int. J. of Heat and Mass Transfer, Vol. 47, pp. 3257-3268.

Dhir, V.K., 2006, Mechanistic Prediction of Nucleate Boiling Heat Transfer - Achievable or a Hopeless Task?, J. Heat Transfer, Vol. 128, pp.1-12.

Gjerkěs, H. and Golobič, I., 2001, Interactions between laser-activated nucleation sites in pool boiling, Int. J. Heat Mass Transfer, Vol. 44, pp. 143-153.

Gjerkěs, H. and Golobič, I., 2003, Measurement of certain parameters influencing activity of nucleation sites in pool boiling, Experimental Thermal Fluid Science, Vol. 25, pp.487-493.

Golobič, I., Pavlovič, E., Strgar, S., Kenning, D.B.R. and Yan, Y., 1996a, Wall Temperature Variations During Bubble Growth on a Thin Plate: Computation and Experimentations, Proc. Eurotherm Seminar No. 48, Pool Boiling 2, Paderborn, pp.25-32.

Golobič, I., Pavlovič, E., and Strgar, S., 1996b, Computer Model for Nucleation Site Interactions on a Thin Plate, Proc. Eurotherm Seminar No. 48, Pool Boiling 2, Paderborn, pp. 33-42.

Golobič, I., Pavlovič, E., von Hardenberg, J., Berry, M., Nelson, R.A., Kenning, D.B.R. and Smith, L.A., 2004, Comparison of a Mechanistic Model for Nucleate Boiling with Experimental Spatio-temporal Data, Chemical Engineering Research and Design, Vol. 82, pp. 435-444.

Golobič, I., Petkovsek, J., Baselj, M., Papez, A., Kenning, D.B.R., 2007a, Experimental determination of transient wall temperature distributions close to growing vapor bubbles, Heat Mass Transfer On-line DOI 10.1007/S00231-007-0295-y.

Golobič, I., Petkovsek, J. and Kenning, D.B.R., 2007b, Bubble growth and horizontal coalescence in saturated pool boiling on a thin foil, investigated by high-speed IR thermography, Int. J. Heat Mass Transfer (submitted).

Kenning, D.B.R., Golobič, I., Xing, H., Baselj, M., Lojk, V. and von Hardenberg, J., 2006, Mechanistic Models for Pool Nucleate Boiling Heat Transfer: Input and Validation, Heat and Mass Transfer Vol. 42, pp. 511527.

Mukherjee, A. and Dhir, V.K., 2004, Study of Lateral Merger of Vapor Bubbles During Nucleate Pool Boiling, J. Heat Transfer Vol. 126, pp. 1023-1039.

Mosdorf, R. and Shoji, M., 2004, Chaos in nucleate boiling - nonlinear analysis and modelling, Int. J. Heat Mass Transfer, Vol. 47, pp. 1515-1524.

Myers, J.G., Yerramilli, V.K., Hussey, S.W., Yee, G.F. and Kim, J., 2005, Time and Space Resolved Wall Temperature and Heat Flux Measurements During Nucleate Boiling with Constant Heat Flux Boundary Conditions, Int. J. of Heat and Mass Transfer, Vol. 48, pp. 2429-2442.

Nelson, R.A, Kenning, D.B.R. and Shoji, M., 1996, Nonlinear Dynamics in Boiling Phenomena, J. Heat Transfer Society of Japan, Vol. 35, pp. 22-34. 
Pasamehmetoglu, K.O. and Nelson, R.A., 1991, Cavity-to-Cavity Interaction in Nucleate Boiling: the Effect of Heat Conduction within the Heater, AIChE Symposium Series (27th Nat. Heat Transfer Conf., Minneapolis), Vol. 87, pp. 342-351.

Rule, T.D. and Kim, J., 1999, Heat Transfer Behavior on Small Horizontal Heaters During Pool Boiling of FC-72, J. of Heat Transfer - Trans. of the ASME, Vol. 121, pp. 386-393.

Sadasivan, P., Unal, C. and Nelson, R.A., 1995, Nonlinear Aspects of High Heat Flux Nucleate Boiling, J. Heat Transfer, Vol. 117, pp. 981-989.

Sanna, A., Simulation and experimental investigation of pool boiling on a silicon wafer with artificial nucleation sites, Eurotherm conference on Thermal Science, Eindhoven, 2008, (submitted).

Sato, T. and Koizumi, Y., 2007, Experimental Study on Fundamental-Microscopic Mechanism of Boiling by using MEMS Technique (Examination from Aspect of Time Series Chaos Analysis), Proceedings of the Fifth International Conference on Nanochannels, Microchannels and Minichannels, Puebla, Mexico.

Shoji, M., Zhang, L. and Chatpun, S., 2005, Nucleation Site Interaction in Pool Nucleate Boiling - Serial Experiments Using Artificial Boiling Surfaces, Nusselt-Reynolds Prize Lecture, 6th World Conference on Experimental Heat Transfer, Fluid Mechanics and Thermodynamics, Matsushina.

Stephan, P. and Hammer, J., 1994, A New Model for Nucleate Boiling Heat Transfer, Wärme- und Stoffübertragung, Vol. 30, pp. 119-125.

Zhang, L. and Shoji, M., 2003, Nucleation Site Interaction in Pool Boiling on the Artificial Surface, Int. J. of Heat and Mass Transfer, Vol. 46, pp. 513-522.

3M Speciality Materials, 2000, Fluorinert Electronic Liquid FC-72, Product information. 